\section{Coprophagy in the Wild Rabbit}

REPORTS of recent exporiments by Madsen ${ }^{1}$ and Eden $^{2}$ have shown refection to be a normal physiological process in the laboratory rabbit. A few observations collected by me, while studying the ecology and population dynamies of the wild rabbit, suggest that this process also occurs in natural conditions. From Eden's experiments, 54-82 per cent of fæces passed are shown to be normally refected, the advantage of the process to the rabbit being equivalent to "chewing the cud". It is possible that there is a further ecological advantage, which operates under wild conditions.

The population studied by me was that of a warren near Oxford, and a little more than 50 per cent of them were trapped during 1939 and marked in the ear with numbered celluloid disks, so that observations could be made from a neighbouring 'hide' and the individuals and sexes identified by means of a telescope.

Most of these observations (March 1939 to date) were made in the late afternoon, the time when wild rabbits become active and come out to feed. Generally the period of feeding activity is preceded by about half an hour, in which some, at any rate, of the inhabitants are sitting about basking or eleaning themselves. About a hundred observations (15-60 minutes) have been made to date at this hour. Another period of feeding activity is during the late night and early morning, and this is often followed by quite a long period of basking and cleaning, especially in sunny weather, though only about 5 per cent of the population remain to do this, as contrasted with 33 per cent, which is the average proportion observed feeding. About thirty morning observations have been made. In addition, about twelve observations have been made in the early afternoon during the winter. Rabbits may exceptionally feed and bask at this time, according to weather conditions.

In all these observations refection has been observed on four occasions, three times in the early morning and once in the early afternoon. It may seem curious after noting the high proportion of total fæces refected in Eden's experiments, that this was not observed more frequently ; but in the first place it evidently occurs largely at night, and secondly most of it probably occurs in the burrows. It may in fact only happen rarely above ground, so that a long series of observations, such as these, is needed to record it at all. It is clear from the observations that little, if any, coprophagy takes place in the evening, even when basking and lying out occur, and that the morning is the more usual time. This is to be expected from the rhythm demonstrated by Madsen. The one afternoon observation may have been due to exceptional weather conditions (see below).

The method of taking the fæcal pellets was not the same in every case, and the rhythm also varied. One doe was watched at 7 a.m. in August; she extended one hind leg, lifted up the foreleg and bent the head straight down. Another doe, watched at the same time, in September, leaned over on one flank and bent the head round and down outside both forelegs. A third, a buck, watched at 2.30 p.m. in December, did the same as the latter without leaning over on the flank. The two does took pellets at the rate of one every 5 seconds for about 45 seconds. while the buck watched in the afternoon took them at the rate of one every 30 seconds for 3 minutes. 'One pellet' may, of course, mean a group of pellets evacuated simultaneously. The fourth instance watched was at another warren too far away for details to be made out well.

The afternoon observation was made during very cold weather, when the ground was frozen and food difficult to obtain. In this way the rabbit's coprophagy may well be of ecological importance, enabling it to do without a supply of fresh food for certain periods. I examined three rabbits, which had lain up in a bury for at least three days (the length of time traps had been set at the entrances) and in each case the stomach contained a small amount of brownish material very different in appearance from a fresh grass meal. This almost certainly consisted of fæcal pellets broken up. They must have been taken some hours before, since they showed none of the usual 'stomach pellet' shape or discreteness well known to me from examination of normal live rabbit stomachs.

Thus during difficult periods or when scared into 'lying up' during trapping operations, the rabbit may increase the degree of refection. It would be interesting in this connexion to have counts of normal diurnal pellets produced under different environmental conditions. The ability of the rabbit to lie up for as much as a week at a time in unfavourable conditions is remarkable and is an important factor in forming policies of extermination. The degree to which refection is bound up with this ability is also important and deserves further attention.

H. N. Southern.

Bureau of Animal Population,

University Museum,

Oxford.

Jan. 13.

'Madsen, H., "Does the Rabbit Chew the Cud ?" NATure, 143, 981 (1939).

2Eden, A., "Coprophagy in the Rabbit", NATURE, 145, 36 (1940).

\section{Growth Behaviour of Plants following Seed Treatment by Organic Mercury Compounds}

Albinism in citrus seedlings is not uncommon. Frost ${ }^{1}$ suggests that its frequent production by some parents may be due primarily to heterozygosis for various genes for albinism, and perhaps to the presence of unstable genes such as occur in cases of variegation in other plants.

Successful control of seedling albinism in citrus has been achieved in Palestine ${ }^{2}$ by treating the seeds in a 1 : 1,000 solution of 'Uspulun' or 'Ceresan' in water.

In this connexion, Perlberger and Reichert ${ }^{3}$ state that albinism can also be controlled by dipping the seeds in salt solutions of other metals, including lead, copper, cobalt and nickel. From this they argue that albinism in citrus is a constitutional property inherent in the plant, which manifests itself only at germination and is probably due to a disturbance of the enzymatic systems of the plant at this stage. This is borne out by the fact that salts of heavy metals which are known to have an effect on enzymatic systems cause citrus seeds to produce normal seedlings. 